\title{
Evaluación del contenido nutrimental de leches saborizadas
}

Evaluation of Nutritional Content of Flavored Milk

\author{
Karla A. Pérez-Hernández ${ }^{a}$, Karla Meneses-Orozco ${ }^{b}$, Samantha Bouzas-Linares ${ }^{c}$, Diana L. \\ Ortega $^{d}$, Esther Ramírez-Moreno ${ }^{e}$, Claudia Valadez-Serrano $^{f}$
}

\begin{abstract}
:
Flavoured milk is a product obtained from whole, skim or partially skim milk, which is added with flavourings and / or flavourings, as well as ingredients such as additives, sweeteners and stabilizers. They provide a good content of calcium and vitamin D.

The objective of this work was to review the nutritional quality and presence of flavoured milk additives, considering what is established by the standards for these products. In general, these milks presented a good contribution of protein, calcium and vitamin $\mathrm{A}$ and D, complying with what is stipulated in the NOM that regulates these products, however the sugar content exceeds the values established by said norm. The commercial presentation of these products presents colours and figures alluding to children's characters, generating greater visual attraction for children.
\end{abstract}

Therefore, milk is a product rich in calcium, protein and vitamin $\mathrm{A}$ and $\mathrm{D}$, however, its consumption should be moderate since it has a high amount of added sugars and dyes that can affect the health of those who consume it. special to the child population to whom this product is directed.

\section{Keywords:}

Milk, flavored milk, nutritional content, additives

\section{Resumen:}

La leche saborizada es un producto obtenido a partir de la leche entera, descremada o parcialmente descremada, la cual es adicionada con saborizantes y/o aromatizantes, además de ingredientes como aditivos, edulcorantes y estabilizantes. Aportan un buen contenido de calcio y vitamina $D$.

El objetivo del presente trabajo fue realizar una revisión de la calidad nutricional y presencia de aditivos de leches saborizadas, considerando lo que establece las normas para estos productos. En general estas leches presentaron un buen aporte de proteína, calcio y vitamina A y D cumpliendo con lo que estipula la NOM que regula estos productos, sin embargo, el contenido de azucares sobrepaso los valores establecidos por dicha norma. La presentación comercial de estos productos presenta colores y figuras alusivas a personajes infantiles, generando mayor atracción visual para la población infantil.

Por lo tanto, las leches son un producto rico en calcio, proteína y vitamina A y D, sin embargo, su consumo debe ser moderado ya que presenta una alta cantidad de azucares añadidos y colorantes que pueden afectar la salud de quien lo consume, en especial a la población infantil a quien está dirigido este producto.

\section{Palabras Clave:}

Leches saborizadas, contenido nutricional, aditivos

\footnotetext{
a Autor de Correspondencia, Universidad Autónoma del Estado de Hidalgo, Instituto de Ciencias de la Salud, Email: aleh29ph@gmail.com

${ }^{\text {b }}$ Universidad Autónoma del Estado de Hidalgo, Instituto de Ciencias de la Salud, Email: karla_meneses22@hotmail.com

${ }^{c}$ Universidad Autónoma del Estado de Hidalgo, Instituto de Ciencias de la Salud, Email: sam.bouzas01@ gmail.com

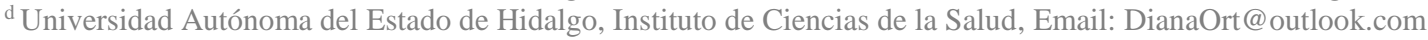

e Autor de principal, Universidad Autónoma del Estado de Hidalgo, Instituto de Ciencias de la Salud, Email: esther_ramirez@uaeh.edu.mx

${ }^{\mathrm{f}}$ Universidad Autónoma del Estado de Hidalgo, Instituto de Ciencias de la Salud, Email: valadez8@ hotmail.com
} 


\section{Introducción}

Los productos lácteos se caracterizan por contribuir con un aporte importante de proteína y ser una fuente importante de calcio y vitamina D. ' ${ }^{1}$ La leche saborizada, es el producto obtenido a partir de la leche entera, descremada o parcialmente descremada, apta para el consumo, saborizada y/o aromatizada con ingredientes o aditivos alimentarios autorizados, sometida a tratamiento UHT o esterilizada, a la que se ha adicionado saborizantes, edulcorantes y estabilizantes autorizados en la NOM-155-SCFI-2012 con el objeto de obtener un producto con caracteres organolépticos diferentes. ${ }^{2}$

Además, debe contener al menos el $85 \%$ de leche apta para consumo humano. ${ }^{3}$ El porcentaje restante puede estar constituido por fruta, colorantes, aditivos o espesantes.

En México, $10.7 \%$ del gasto en productos de consumo masivo de los hogares es destinado a la leche líquida, representando un alto consumo en los hogares mexicanos. La Organización de las Naciones Unidas para la Alimentación y la Agricultura (FAO, por sus siglas en inglés) recomienda consumir por lo menos $500 \mathrm{~mL}$ de leche diarios (180 $\mathrm{L}$ anuales), sin embargo, en nuestro país no se cumple con estas recomendaciones, ya que el consumo per cápita es de $340 \mathrm{~mL}$ (130 L anuales). ${ }^{4}$

El mercado de los productos de la leche ha crecido en diversidad, por lo que las presentaciones de leches de sabor han ido cambiando. México ocupa el séptimo lugar en consumo de productos lácteos a nivel global de los cuales 350 millones de litros son de leches saborizadas, principalmente chocolate. De acuerdo a estos valores se sabe que el consumo de leche es bajo y un gran porcentaje de este consumo es de leche saborizada.

Actualmente, el aporte energético y nutritivo de estos productos resulta relevante con el creciente problema de sobrepeso en los niños y población en parte por la preferencia en el consumo de productos con azucares añadidos. ${ }^{5}$

\section{Objetivo}

Evaluar la calidad nutricional y aditivos considerando el etiquetado de leches saborizadas adquiridas en supermercados de Pachuca, Hidalgo.

\section{Metodología}

Se seleccionaron marcas de leche saborizada en tres presentaciones (chocolate, fresa y vainilla): Santa Clara,
Lala, Alpura, Altea, Great Value y Nesquik, expendidas en supermercados ubicados en Pachuca, Hidalgo.

Se registró la información por $100 \mathrm{~mL}$ de producto y se consideró calorías, proteína, lípidos, hidratos de carbono, fibra, sodio, calcio, vitaminas A y D y el precio. Además, se consideraron los aditivos presentes en las leches saborizadas. Se revisó que estos productos cumplieran con las Normas NMX-183- SCFI-2012, NMX-155-SCFI2012 y NMX-243- SSA1- 210.

\section{Resultados y discusión}

Tabla 1. Contenido nutricional de leches sabor chocolate.

\begin{tabular}{|c|c|c|c|c|c|c|}
\hline & $\begin{array}{l}\text { Santa } \\
\text { Clara }\end{array}$ & Lala & Alpura & Altea & $\begin{array}{l}\text { Great } \\
\text { Value }\end{array}$ & Nesquik \\
\hline $\mathrm{mL} /$ Envase & 240 & 250 & 250 & 250 & 250 & 240 \\
\hline Kcal & 85 & 56 & 54.8 & 66.8 & 66.8 & 51.25 \\
\hline Proteína g & 3 & 2.64 & 2.92 & 3 & 3 & 2.66 \\
\hline Lípidos g & 1.8 & 1.4 & 1.52 & 1.6 & 1.6 & 1.25 \\
\hline $\mathrm{HCO} \mathrm{g}$ & 14.2 & 8.2 & 7.04 & 10.1 & 10.1 & 7.3 \\
\hline Fibra g & 0 & 0.56 & 0 & 0 & 0 & 0 \\
\hline Sodio mg & 40 & 57.2 & 60.8 & 50 & 50 & 60.5 \\
\hline Calcio mg & 140 & 94 & 103.6 & 103.2 & 103.2 & 93.9 \\
\hline Vit. A Mg & 61.2 & 60 & 36 & 66.4 & 66.4 & 31.41 \\
\hline Vit. D Mg & 0.6 & 0.6 & 0.69 & 0.5 & 0.5 & 0.5 \\
\hline Precio & 10 & 11 & 11.5 & 6 & 5 & 12 \\
\hline
\end{tabular}

Tabla 2. Contenido nutricional de leches sabor vainilla

\begin{tabular}{lllllll}
\multicolumn{2}{l}{ Leche sabor vainilla } & \multicolumn{1}{l}{ Lala } & Alpura & Altea & $\begin{array}{l}\text { Great } \\
\text { Value }\end{array}$ & Nesquik \\
& Clara & & & & \multicolumn{1}{l}{ La } & \\
\hline mL/Envase & 240 & 250 & 250 & 250 & 250 & 240 \\
Kcal & 62.9 & 53.2 & 54.8 & 66.8 & 66.8 & 51.25 \\
Proteína g & 3 & 2.64 & 2.92 & 3 & 3 & 2.66 \\
Lípidos g & 1.8 & 1.4 & 1.52 & 1.6 & 1.6 & 1.25 \\
HCO g & 8.7 & 7.48 & 7.04 & 10.1 & 10.1 & 7.3 \\
Fibra g & 0 & 0.56 & 0 & 0 & 0 & 0 \\
Sodio mg & 40 & 57.2 & 60.8 & 50 & 50 & 60.5 \\
Calcio mg & 140 & 94 & 103.6 & 103.2 & 103.2 & 93.9 \\
Vit. A Mg & 61.2 & 60 & 36 & 66.4 & 66.4 & 31.41 \\
Vit. D Mg & 0.6 & 0.6 & 0.69 & 0.5 & 0.5 & 0.5 \\
Precio & 10 & 11 & 11.5 & 6 & 5 & 12 \\
\hline
\end{tabular}

Tabla 3. Contenido nutricional de leches sabor fresa.

Leche sabor fresa

\begin{tabular}{lllllll}
\hline & $\begin{array}{l}\text { Santa } \\
\text { Clara }\end{array}$ & Lala & Alpura & Altea & $\begin{array}{c}\text { Great } \\
\text { Value }\end{array}$ & Nesquik \\
\hline mL/Envase & 240 & 250 & 250 & 250 & 250 & 240 \\
Kcal & 77.5 & 56 & 54.8 & 66.8 & 66.8 & 51.25 \\
Proteína g & 3 & 2.64 & 2.92 & 3 & 3 & 2.66 \\
Lípidos g & 1.8 & 1.4 & 1.52 & 1.6 & 1.6 & 1.25 \\
HCO g & 12.33 & 8.2 & 7.04 & 10.1 & 10.1 & 7.3 \\
Fibra g & 0 & 0.56 & 0 & 0 & 0 & 0 \\
Sodio mg & 40 & 57.2 & 60.8 & 50 & 50 & 60.5 \\
Calcio mg & 140 & 94 & 103.6 & 103.2 & 103.2 & 93.9 \\
Vit. A Mg & 61.2 & 60 & 36 & 66.4 & 66.4 & 31.41 \\
Vit. D Mg & 0.6 & 0.6 & 0.69 & 0.5 & 0.5 & 0.5 \\
Precio & 10 & 11 & 11.5 & 6 & 5 & 12 \\
\hline
\end{tabular}

Todas las leches revisadas cumplieron con lo establecido en la norma NOM-183- SCFI-2012, la cual establece que la leche debe contener un mínimo de proteína de 2 g/ 100 
$\mathrm{mL}$ de leche. De acuerdo a la NOM-155-SCFI-2001 todas las leches evaluadas se encontraron en el rango de 0.6 a $2.8 \mathrm{~g} / 100 \mathrm{~mL}$ de grasa para una leche semidescremada.

Por otro lado, el contenido de hidratos de carbono en estas "lechitas" sobrepasa los valores establecidos por la NOM183-SCFI-2012 (4-5 g/100 mL), con valores entre 7 y 14 $\mathrm{g} / 100 \mathrm{~mL}$, lo cual proviene de la lactosa y de los azucares añadidos. 6 En nuestro país el consumo de estos productos es alarmante en la población infantil, sobre todo por el contenido de estos azúcares añadidos. Dicho consumo está relacionado con el desarrollo de enfermedades como sobrepeso y obesidad y sobre todo de caries dentales en la población infantil. ${ }^{7}$

De acuerdo con la normativa estos productos deben cumplir con las especificaciones establecidas de calcio $(96.3 \mathrm{mg})^{8}$, vitamina A (31 a $67 \mu \mathrm{g}$ equivalentes de retinol, NOM-243- SSA1- 2010) y Vitamina D (0.5- $0.75 \mu \mathrm{g})$ por cada $100 \mathrm{~mL}$ de leche, por lo que ninguno de los productos evaluados se encuentra fuera de los rangos establecidos. 9

El consumidor debe considerar que estos productos además de contener un alto contenido de azucares, son productos caros si consideramos el costo del producto por litro de $\$ 20.00$ pesos. La presentación de estos productos varía entre 240 y $250 \mathrm{~mL}$ y el costo es de 6 hasta 12 pesos, justificado por el mayor procesamiento y la utilización de aditivos, sin considerar todo el costo de la comercialización del producto. Lo anterior afecta considerablemente al bolsillo del consumidor.

Tabla 4. Aditivos y edulcorantes presente en leches saborizadas

\begin{tabular}{|c|c|c|c|c|c|}
\hline Aditivos & $\begin{array}{l}\text { Sta. } \\
\text { Clara }\end{array}$ & Lala & Alpura & Altea & $\begin{array}{l}\text { G. } \\
\text { Value }\end{array}$ \\
\hline Grasa Butírica & + & + & + & + & + \\
\hline A. Ascórbico & & & & + & + \\
\hline A. Cítrico & + & + & + & + & + \\
\hline A. Láctico & + & * & + & + & * \\
\hline Acesulfame k1 & & & + & & \\
\hline Sucralosa & & & 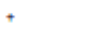 & & \\
\hline Estabilizantes & + & + & + & + & + \\
\hline Carboximetilcelulosa de $\mathrm{Na}$ & & & & * & + \\
\hline Goma Guar & & + & $*$ & & \\
\hline Goma xantán & + & & & + & \\
\hline Saborizante (Estevia) & & + & + & * & + \\
\hline
\end{tabular}

En la tabla 4 se presenta los aditivos y edulcorantes presentes en las leches saborizadas, los cuales están permitidos de acuerdo a lo establecido en la NOM-243SSA1-2010: ácido ascórbico, ácido cítrico, ácido fosfórico, ácido láctico, ascorbato de calcio, goma guar. ${ }^{10}$ Estos productos se utilizan principalmente como acidificantes y conservadores de frescura (ácido ascórbico, cítrico, fosfórico y láctico) y para impedir o retrasar la aparición de una textura granulosa, ejerciendo un efecto muy positivo sobre la textura e impartiendo viscosidad dando una sensación de cremosidad (goma guar). ${ }^{11}$

Estos productos no deben contener fibra dietética, sin embargo, del total de las 18 leches analizadas se observó que la marca Lala en sus tres presentaciones (chocolate, vainilla y fresa) fueron las únicas que presentaron fibra $(0.56 \mathrm{~g} / \mathrm{mL})$. Lo anterior debido a la adición de gomas (guar y celulosa) que se utilizan como espesantes para dar consistencia al producto. El consumo moderado no genera daño, pero un consumo frecuente puede ocasionar efecto laxante. ${ }^{8}$

Las leches saborizadas no son consideradas productos altos en sodio ya que no sobrepasan los $140 \mathrm{mg}$ por porción (NOM-086-SSA1-1994) con excepción de la leche Lala de vainilla $(160 \mathrm{mg} / 250 \mathrm{~mL}){ }^{9}$

Tabla 5. Colorantes presentes en leches saborizadas

\begin{tabular}{lc}
\hline & Colorantes presentes \\
\hline Sabor & Colorante \\
\hline Chocolate & Rojo 40 y azul \\
Vainilla & Amarillo 6 \\
Fresa & Rojo Allura AC \\
\hline \multicolumn{2}{c}{ Lala } \\
\hline Chocolate & Natural Cocoa \\
Vainilla & Amarillo 6 \\
Fresa & Rojo 40 y Rojo 3 \\
\hline \multicolumn{2}{c}{ Alpura } \\
\hline Chocolate & Natural Cocoa \\
Vainilla & Amarillo 6 \\
Fresa & Rojo Allura AC \\
\hline & Altea \\
\hline Chocolate & Natural Cocoa \\
Vainilla & Amarillo Ocaso \\
Fresa & Rojo Allura AC \\
\hline \multicolumn{2}{c}{ G. Value } \\
\hline Chocolate & Rojo 40 y azul 1 \\
Vainilla & Amarillo artificial \\
Fresa & Rojo Allura AC \\
\hline
\end{tabular}

En la Tabla 5 se pueden observar los colorantes utilizados en las leches, estos se utilizan para mejorar su aspecto y ser más atractivo. Los colorantes encontrados en estos productos son aditivos permitidos en la NOM - 243- SSA1210: azafrán o amarillo 6 natural, azul, rojo 3 , rojo allura AC, natural cocoa, caramelo, rojo natural 40 naranja 8 y amarillo ocaso. ${ }^{10} \mathrm{El}$ consumo excesivo de estos productos o de otros alimentos procesados que contienen colorantes está relacionado con la aparición de alergias, por lo que el consumo de estos productos debe ser moderado.

Finalmente, un aspecto importante es la presentación comercial en su envase, estos productos se caracterizaron por colores llamativos y figuras alusivos a personajes infantiles que ocasiona una mayor preferencia en la población infantil. Si el producto no 
contiene frutas entre sus ingredientes como son: jugo, pulpa o mermelada, no podrá figurar en el rótulo ninguna representación gráfica relativa a las mismas debido a que genera confusión al consumidor generando una mayor preferencia del producto. ${ }^{12}$ Ninguno de los productos presentó frutas en los ingredientes y por lo tanto tampoco incluyeron figuras de frutas en la presentación.

\section{Conclusión}

Las leches saborizadas son productos con un adecuado contenido de proteína, calcio y vitaminas A y D, sin embargo, presentan azucares añadidos que sobrepasan el contenido establecido por la norma NMX-243-SSA1210.

De igual manera estos productos contienen aditivos que ayudan a aumentar su vida de anaquel, y la apariencia de las leches saborizadas, como son los acidulantes, conservadores, gomas y colorantes.

Por lo tanto, el consumo de estos productos debe ser prudente sobre todo en la población infantil, prefiriendo presentaciones con menor costo y con menos cantidad de azucares y aditivos.

\section{Referencias}

[1] PROFECO. (2015). Leches y productos lácteos combinados.

[2] NOM-155-CSFI-2012. Leches-denominaciones, especificaciones fisicoquímicas, información comercial y métodos de prueba

[3] Kuklinsky, C. (2003). Nutrición y Bromatología. Barcelona: Omega. Pp 2016-2017.

[4] FAO (2017), Codex alimentarios, leches y productos lacteos. Acesso: 12/ Marzo/ 2019

[5] Revista Enfasis de Alimentacipn (2019). Prefiere leche saborizada.

[6] NOM- 183-SCFI-2012. Producto lácteo y producto lácteo combinadoDenominaciones, especificaciones fisicoquímicas, información comercial y métodos de prueba.

[7] Cabezas, C., Hernández, B., Vargas, M. (2016). Azúcares adicionados a los alimentos: efectos en la salud y regulación mundial. Rev. Fac. Med, 64(3): 319-29.

[8] Espinosa A., Zapata L. (2010). Estudio de leches saborizadaspresentación 200mL. Pp 5-7.

[9] NOM-086-SSA1-1994, BIENES Y SERVICIOS. ALIMENTOS Y BEBIDAS NO ALCOHOLICAS CON MODIFICACIONES EN SU COMPOSICION. ESPECIFICACIONES NUTRIMENTALES.

[10] NOM - 243- SSA1- 210. Productos y servicios. Leche, formula láctea, producto lácteo combinado y derivados.

[11] Badui, S. (2012). La ciencia de los alimentos en la práctica. México. Editorial:PEARSON. Pp: 149- 158.

[12] La leche y los productos lácteos, Reglamento sanitario de los alimentos. 